\title{
Release and re-hook: a novel method with com- bined use of clips and nylon snare to close a colonic defect after endoscopic mucosal resection
}

A 67-year-old man presented to our department for a screening colonoscopy, during which a 2-cm type Ila nonpolypoid lesion was found in the ascending colon $(\bullet$ Fig.1a). After submucosal injection (saline with methylene blue) and adequate lifting of the lesion, a single-piece endoscopic mucosal resection (EMR) was performed. The post-EMR defect consisted only of serosal lining ( $\bullet$ Fig. 1 b).

Because of its large size, attempts to close the defect with clips failed. A decision was made to close the defect with the combined use of clips and a nylon snare (HX400U; Olympus, Tokyo, Japan). The traditional method of snaring and clipping could not be performed. Therefore, we developed a new technique.

At the patient's bedside, the nylon snare was opened and released from its original sheath ( $\bullet$ Fig. 2 a). The distal loop of the snare was enlarged to facilitate re-hooking ( $\bullet$ Fig.2b). The snare was grasped with a clip (QuickClip2; Olympus) and
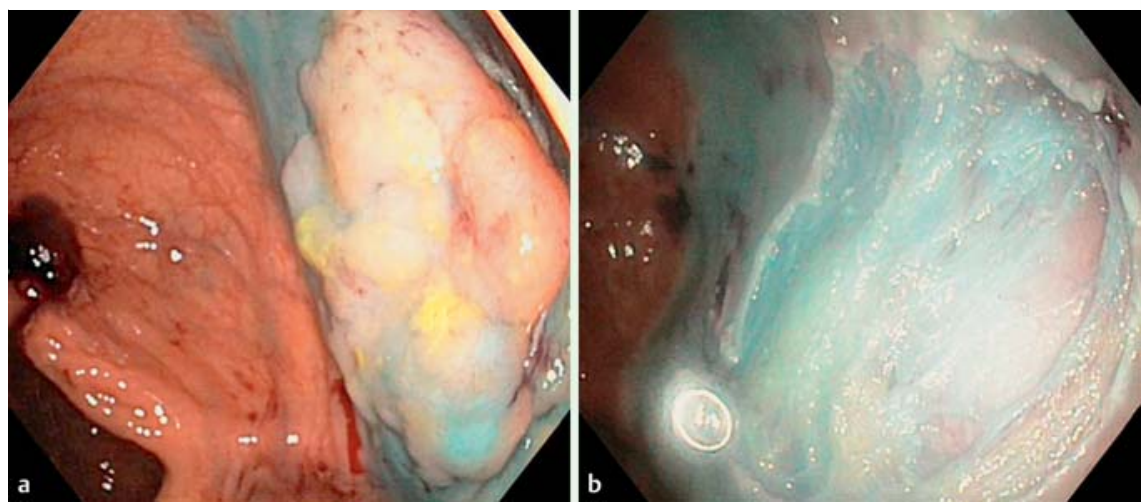

Fig. 1 a Sessile polyp and positive lifting sign in the ascending colon of a 67-year-old man undergoing screening colonoscopy. $\mathbf{b}$ Colonic wall defect after resection; only the serosal lining is left in situ. Attempts to close the defect with clips failed.
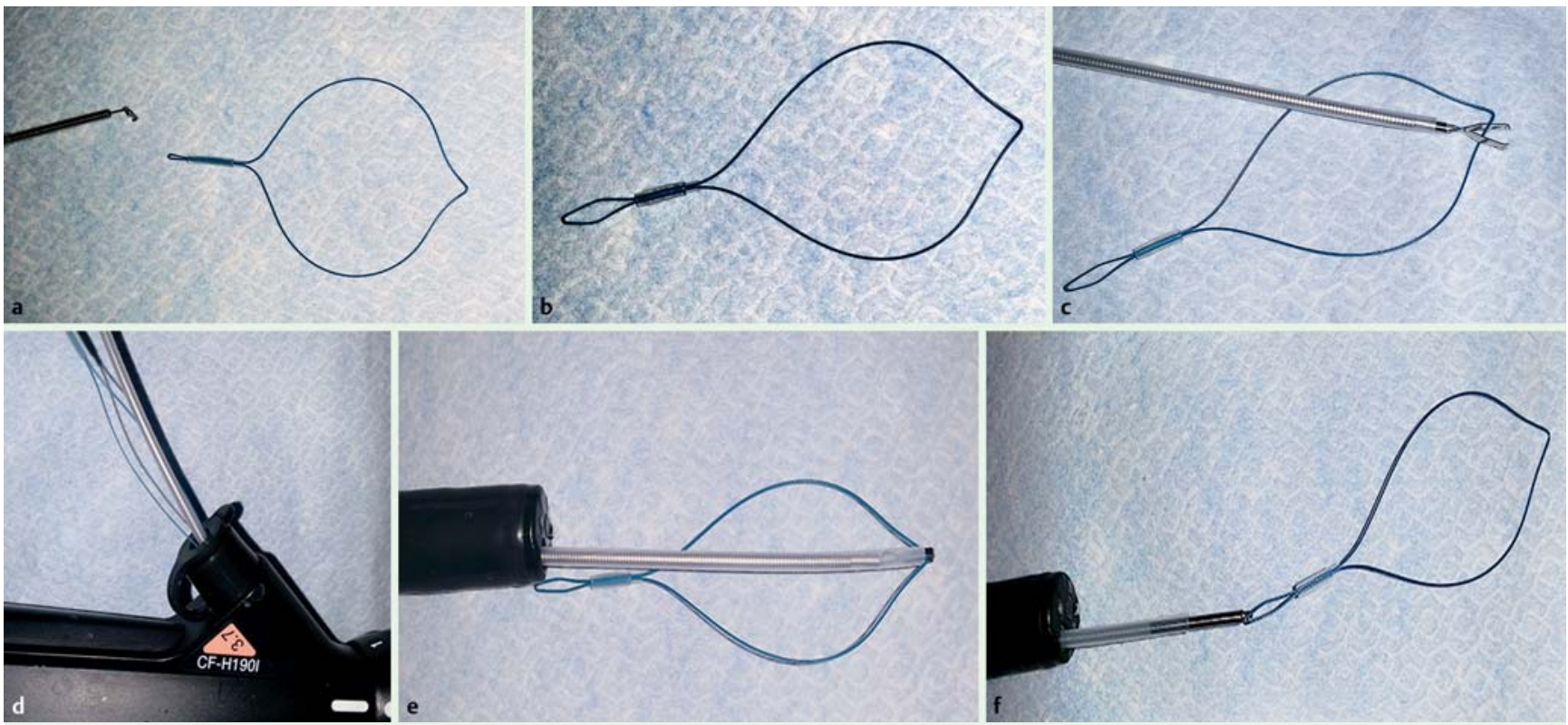

Fig. 2 Release and re-hook method (bedside demonstration). a The snare is released in the open position from the original sheath. $\mathbf{b}$ The distal loop is enlarged to facilitate re-hooking of the snare. $\mathbf{c}$ The snare is grasped with a clip. $\mathbf{d}$ The snare is introduced through the working channel of the colonoscope. e Delivery of the snare. $\mathbf{f}$ Re-hooking of the snare. 

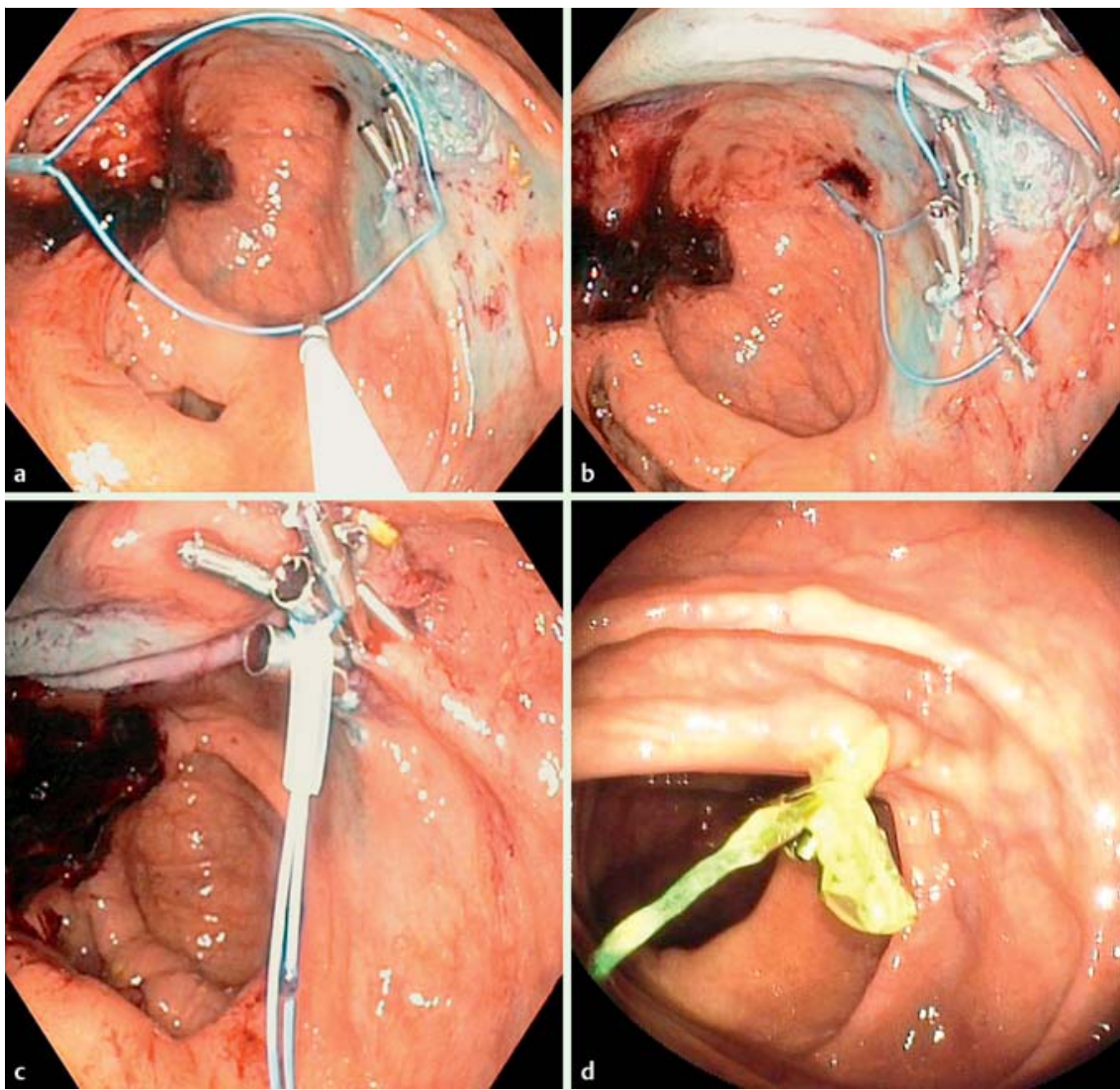

Fig. 3 Combined use of a nylon snare and clips for closure of the colonic wall defect. a Delivery of the snare into the colonic lumen. $\mathbf{b}$ Anchoring the snare with clips along the edges of the defect. $\mathbf{c}$ The closure is done in a "purse-string" fashion. $\mathbf{d}$ Follow-up colonoscopy at 8 weeks shows complete healing of the defect, with both snare and clips in situ.

In sum, we believe that our release and rehook method is a useful modification of the snare-and-clip technique and might be useful in a clinical scenario such as the one presented here.
Hrvoje Ivekovic, Dejan Vrzic, Branko Bilic, Nadan Rustemovic, Rajko Ostojic

University Hospital Centre Zagreb, Department of Gastroenterology and Hepatology, Zagreb, Croatia

\section{References}

1 Luigiano C, Ferrara F, Polifemo $A M$ et al. Endoscopic closure of esophageal fistula using a novel "clips and loop" method". Endoscopy 2009; 41: E249-E250

2 Zeng CY, Li GH, Zhu Y et al. Single-channel endoscopic closure of large endoscopyrelated perforations. Endoscopy 2015; 47: $735-738$

3 Matsuda T, Fujii T, Emura $F$ et al. Complete closure of a large defect after EMR of a lateral spreading colorectal tumor when using a two-channel colonoscope. Gastrointest Endosc 2004; 60: 836-838

\section{Bibliography}

Dol http://dx.doi.org/

10.1055/s-0034-1393042

Endoscopy 2015; 47: E545-E546

(c) Georg Thieme Verlag KG

Stuttgart · New York

ISSN 0013-726X

\section{Corresponding author}

\section{Hrvoje Ivekovic, MD, PhD}

University Hospital Centre Zagreb

Department of Gastroenterology and Hepatology

Kispaticeva 12

10000 Zagreb

Croatia

Fax: +385-1-2388200

hrvoje.ivekovic@gmail.com 